\title{
HEMODIALYSIS BEFORE URGENT SURGERY IN A PATIENT TREATED WITH DABIGATRAN - A CASE REPORT
}

R. Santos Pinheiro, A. Vasconcelos Pereira, B. Aguiar Tavares da Silva, L. Rego, N. Costa

Vila Franca de Xira Hospital, Anesthesiology, Vila Franca de Xira, Portugal

\section{BACKGROUND}

Dabigatran is a reversable direct thrombin inhibitor with $80 \%$ renal excretion. Fast reversal of anticoagulants' activity may be necessary to urgent surgical procedures and mandatory for neuroaxial anesthesic approach. Hemodialysis should be considered in Dabigatran anticoagulated patients with severe renal failure who require urgent surgery.

\section{CASE-REPORT}

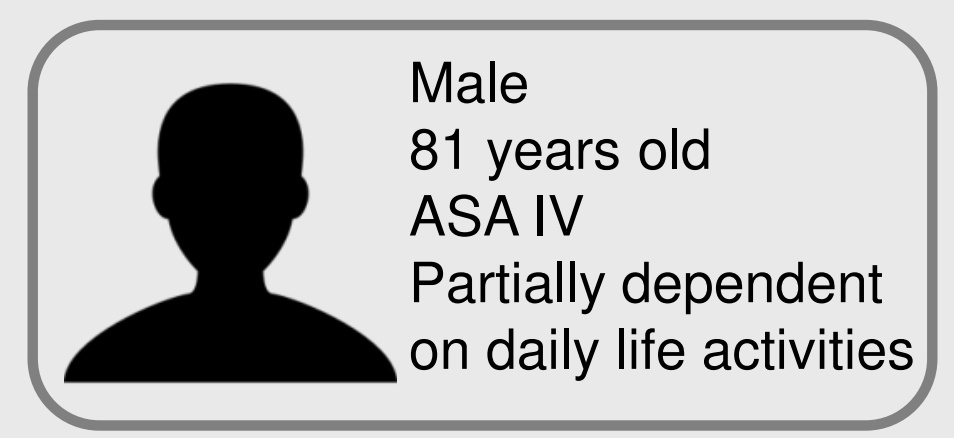

Hypertension

Atrial fibrillation

Chronic heart failure (NYHA IV)

Chronic anemia

COPD

Radiation induced pneumonitis

Type 2 respiratory failure

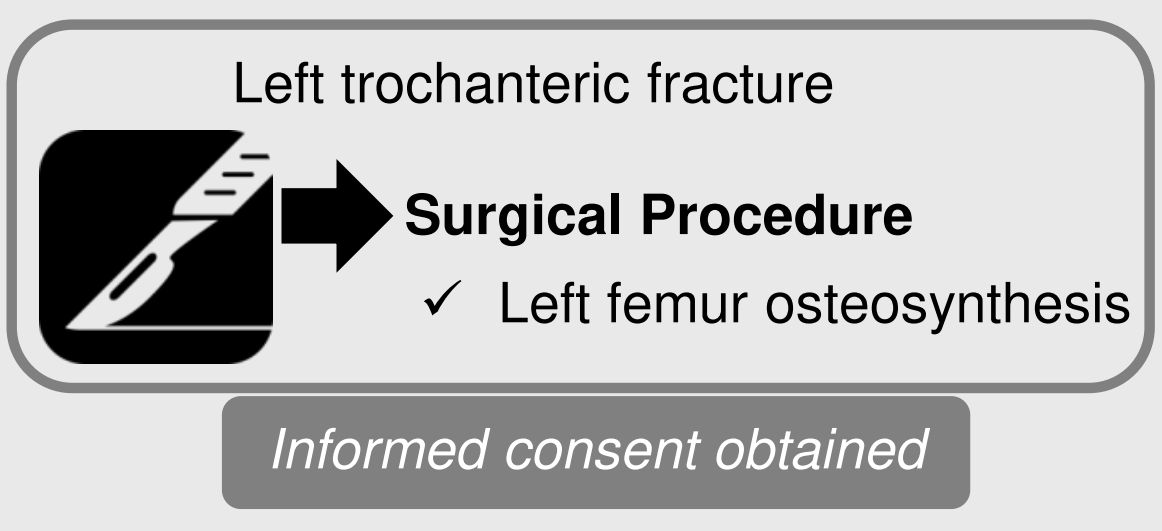

$\mathrm{Hb} 6,8 \mathrm{~d} / \mathrm{dL}$

aPTT56-sec (24-33sec)

Acute renal injury (AKIN III, GFR 26mL/min/1,73m2)

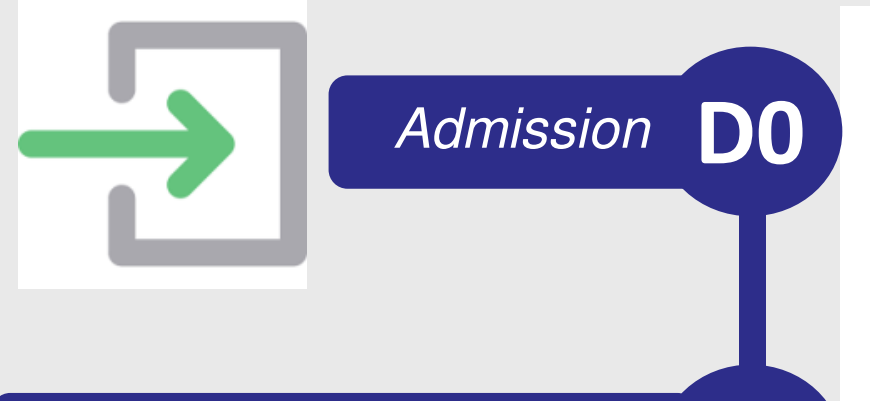

Anemia optimization

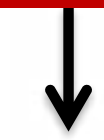

2-units-RBC-concentrate<smiles>CCC(C)[TeH2]</smiles>

Hypocoagulation reversal

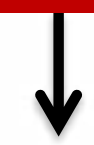

Prothrombin complex concentrate Calcium gluconate

3H Hemodialysis session

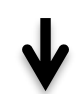
aPTT 36-sec

\section{$2^{\text {st }}$ anesthesia evaluation D2 Fit for surgery}

Anesthesic plan: Spinal Anaesthesia

INTRA-OPERATIVE D3

$\checkmark$ Femur fixation under spinal anesthesia, L3-L4 level, 25G quincke needle, 2 attempts, clear cerebrospinal fluid.

$\checkmark$ The procedure went without any complications.

POST-OPERATIVE D6 He was discharged hemodynamically stable with normal urine output.

\section{DISCUSSION}

Orthopedic surgery has a high hemorrhagic risk and hypocoagulation is common among older orthopedic patients. Dabigatran hypocoagulated patients with impaired renal function (GFR $<30 \mathrm{~mL} / \mathrm{min} / 1,73 \mathrm{~m} 2$ ), require at least a 5 days suspension.

Dabigatran is the only anticoagulant that can be removed through hemodialysis.

Regarding our patient we considered spinal anesthesia a safer option taking in account the risks related to anesthesia recovery, particularly ventilatory weaning.

In patients hypocoagulated with Dabigatran, whose general anesthesia and airway related risks are increased, hemodialysis along with PCC are effective interventions to reduce dabigatran serum levels allowing neuraxial anestesia.

1. Khadzhynov D. et al - Effective elimination of dabigatran by haemodialysis. A phase I single-centre study in patients with end-stage renal disease. Thromb Haemost 2013 Apr;109(4):596-605 